\title{
Adjuvant S-1 chemotherapy after curative resection of gastric cancer in Chinese patients: assessment of treatment tolerability and associated risk factors
}

\author{
Winnie Yeo *, KO Lam, Ada LY Law, Conrad CY Lee, CL Chiang, KH Au, Frankie KF Mo, TH So, \\ KC Lam, WT Ng, L Li
}

\section{A B S T R A C T}

Introduction: The use of adjuvant chemotherapy with S-1 (tegafur, gimeracil, and oteracil potassium) has been shown to improve the outcome of patients with gastric cancer. There are limited data on the tolerability of $\mathrm{S}-1$ in Chinese patients. In this multicentre retrospective study, we assessed the toxicity profile in local patients.

Methods: Patients with stage II-IIIC gastric adenocarcinoma who had undergone curative resection and who had received S-1 adjuvant chemotherapy were included in the study. Patient demographics, tumour characteristics, chemotherapy records, as well as biochemical, haematological, and other toxicity profiles were extracted from medical charts. Potential factors associated with grade 2-4 toxicities were identified.

Results: Adjuvant S-1 was administered to 30 patients. Overall, 19 (63\%) patients completed eight cycles. The most common grade 3-4 adverse events included neutropaenia (10\%), anaemia (6.7\%), septic episode (16.7\%), diarrhoea (6.7\%), hyperbilirubinaemia (6.7\%), and syncope (6.7\%). Dose reductions were made in $22(73.3 \%)$ patients and $12(40.0 \%)$ patients had dose delays. Univariate analyses showed that patients who underwent total gastrectomy were more likely to experience adverse haematological events $(\mathrm{P}=0.034)$. Patients with nodal involvement were more likely to report adverse nonhaematological events $(\mathrm{P}=0.031)$. Patients with a history of regular alcohol intake were more likely to have earlier treatment withdrawal $(\mathrm{P}=0.044)$. Lower body weight $(\mathrm{P}=0.007)$ and lower body surface area
This article was published on 14 Dec 2016 at www.hkmj.org. patient population was similar to that in other Asian patient populations. The awareness of S-1-related toxicities and increasing knowledge of potential associated factors may enable optimisation of S-1 therapy.

\section{Hong Kong Med J 2017;23:54-62}

DOI: $10.12809 / \mathrm{hkmj} 164885$

\author{
${ }^{1}$ W Yeo *, FRCP, FHKAM (Medicine) \\ ${ }^{2}$ KO Lam, MB, BS, FHKAM (Radiology) \\ ${ }^{3}$ ALY Law, MB, BS, FHKAM (Radiology) \\ CCY Lee, FRCP, FRCR \\ ${ }^{5} \mathrm{CL}$ Chiang, MB, ChB, FRCR \\ ${ }^{6} \mathrm{KH} \mathrm{Au}$, FHKCR, FHKAM (Radiology) \\ ${ }^{7}$ FKF Mo, MPhil, PhD \\ ${ }^{2}$ TH So, BChinMed, MB, BS \\ ${ }^{8} \mathrm{KC}$ Lam, FHKCP, FHKAM (Medicine) \\ ${ }^{3} \mathrm{WT} \mathrm{Ng}, \mathrm{MD}$ \\ ${ }^{8} \mathrm{~L} \mathrm{Li}$, FHKCP, FHKAM (Medicine)
}
Department of Clinical Oncology, The Chinese University of Hong Kong, Shatin, Hong Kong
Department of Clinical Oncology, The University of Hong Kong, Pokfulam, Hong Kong
${ }^{3}$ Department of Clinical Oncology, Pamela Youde Nethersole Eastern Hospital, Chai Wan, Hong Kong
${ }^{4}$ Department of Clinical Oncology, Princess Margaret Hospital, Laichikok, Hong Kong
${ }^{5}$ Department of Clinical Oncology, Tuen Mun Hospital, Tuen Mun, Hong Kong
${ }^{6}$ Department of Clinical Oncology, United Christian Hospital, Kwun Tong, Hong Kong
Comprehensive Clinical Trials Unit, Department of Clinical Oncology, The Chinese University of Hong Kong, Shatin, Hong Kong
${ }^{8}$ Department of Clinical Oncology, Prince of Wales Hospital, Shatin, Hong Kong

* Corresponding author: winnieyeo@cuhk.edu.hk

New knowledge added by this study

- In line with the published data, adjuvant S-1 therapy has a tolerable toxicity profile among local patients who have undergone curative resection for gastric cancer. Total gastrectomy and nodal involvement are potential factors associated with adverse events. Lower body weight and lower body surface area are potential factors associated with dose interruptions.

Implications for clinical practice or policy

- For gastric cancer patients in whom adjuvant S-1 therapy is planned, close monitoring of those who have identifiable risk factors may enable early recognition of adverse events during therapy. This may enable earlier intervention with supportive therapy and improve treatment outcome. 


\section{Introduction}

Gastric cancer is the second most common cause of cancer-related mortality worldwide, with 988000 new cases and 736000 deaths per year. ${ }^{1}$ Surgery is the main treatment for operable gastric cancer but recurrence rates are high and about $40 \%$ to $80 \%$ of patients develop relapsed disease after surgery. The use of adjuvant chemotherapy has been shown to improve patient outcome. ${ }^{2-5}$ After curative resection, common adjuvant chemotherapy regimens that have been recently adopted in many parts of Asia include oral administration of S-1 (tegafur, gimeracil, and oteracil potassium) based on the Adjuvant Chemotherapy Trial of S-1 for Gastric Cancer (ACTS-GC) study conducted in Japan, ${ }^{4}$ as well as oxaliplatin-capecitabine combination chemotherapy based on the Capecitabine and Oxaliplatin Adjuvant Study in Stomach Cancer study. ${ }^{5}$ These studies have shown that adjuvant S-1 for 1 year or oxaliplatincapecitabine combination chemotherapy for 6 months following curative gastrectomy with D2 lymph node dissection increases both overall survival (OS) and relapse-free survival in pathological stage II or III gastric cancer., ${ }^{4,5}$

$\mathrm{S}-1$ is an oral anticancer agent comprising tegafur, 5-chloro-2,4-dihydroxypyridine (CDHP), and oteracil potassium (Oxo) at a molar ratio of 1:0.4:1. ${ }^{6}$ Tegafur is a prodrug of 5 -fluorouracil (5-FU); CDHP is a potent reversible inhibitor of 5 -FU degradation; and Oxo is an inhibitor of the enzyme orotate phosphoribosyltransferase (OPRT) that catalyses the phosphorylation of 5-FU. ${ }^{6}$ Pharmacokinetic analyses have confirmed that S-1 has potent antitumour activity, and oral S-1 administration results in a similar serum concentration of 5 -FU to intravenous 5-FU whilst sparing patients the need for continuous intravenous infusion of 5-FU and consequent toxicity. ${ }^{7}$ Nonetheless early studies have also shown that toxicity profiles may differ between Asian and non-Asian patients. In earlier studies in Japanese patients, the dose-limiting toxicity was bone marrow suppression that occurred prior to gastrointestinal adverse events. In contrast, studies in non-Asian patients revealed that diarrhoea associated with abdominal discomfort and cramping was the principal dose-limiting toxicity and bone marrow suppression was not. ${ }^{8}$ This might be due to the varied activity of OPRT between different populations. In fact, OPRT activates 5 -FU in the bowel mucosa; patients with higher OPRT activity might be expected to experience a higher incidence of gastrointestinal adverse effects prior to bone marrow toxicity. ${ }^{9}$

In the ACTS-GC study, the adverse events of adjuvant S-1 were reported to be generally mild, with $65.8 \%$ of patients being able to complete the planned 1 year of therapy. ${ }^{4}$ While it has been known that patients in the West have a different toxicity

\section{華籍胃癌患者接受癌切除後輔助S-1化療的 耐受性和相關危險因素}

\author{
楊明明、林嘉安、羅麗柔、李智仁、蔣子樑、區國雄、
} 巫國輝、蘇子謙、林國智、吳偉裳、李良

引言：研究發現使用S-1（tegafur、gimeracil和oteracil potassium） 的輔助化療可改善胃癌患者的預後。然而, S-1在華籍患者的耐受性 數據仍很有限。這項多中心回顧性研究旨在評估本地胃癌患者對S-1 化療的耐受性和相關危險因素。

方法：研究對象包括完成手術切除和S- 1 輔助化療的II至IIIC期胃癌患 者。從病人紀錄找出患者的人口學數據、腫瘤特徵、化療紀錄, 以及 生化、血液學和其他毒性特徵, 並確定與2-4級毒性副作用相關的潛在 因素。

結果：共30位胃癌患者接受S-1輔助化療。19名患者（63\%）完成8個 週期的 S- 1 輔助化療。最常見的 3 至 4 級不良事件包括嗜中性白血球減 少症 $(10 \%)$ 、貧血 $(6.7 \%)$ 、感染性事件 $(16.7 \%)$ 、腹瀉 $(6.7 \%)$ 高膽紅素血症 $(6.7 \%)$ 和暈厥 $(6.7 \%) \circ 22$ 名患者 $(73.3 \%)$ 的藥物 劑量有減少, 而 12 名患者 $(40.0 \%)$ 延遲化療。單因素分析顯示, 全 胃切除的患者更可能有不良骨髓副作用（ $\mathrm{P}=0.034 ） 。$ 有淋巴結受累 的患者更可能產生不利的非骨髓副作用（ $\mathrm{P}=0.031 ） 。$ 曾定期飲酒的 患者可能比預期提早停止 S- 1 治療 $(\mathrm{P}=0.044)$ 。影響治療劑量的因素 包括較輕體重 $(\mathrm{P}=0.007)$ 和較小的體表面積 $(\mathrm{P}=0.017)$

結論：本地胃癌患者對S-1的耐受性與其他亞洲患者相若。了解S-1相 關的副作用和潛在的相關因素可以優化S-1治療。

profile to their Japanese counterparts, ${ }^{10}$ there are limited data on tolerability of S-1 among Chinese patients. In this multicentre retrospective study, we assessed the toxicity and tolerability profiles of Hong Kong Chinese patients with gastric cancer who had received adjuvant $\mathrm{S}-1$ chemotherapy.

\section{Methods}

This was a retrospective study carrying out between June 2013 and February 2016, and involved six local centres in Hong Kong: Pamela Youde Nethersole Eastern Hospital, Princess Margaret Hospital, Prince of Wales Hospital, Tuen Mun Hospital, Queen Mary Hospital, and United Christian Hospital. This study has been approved by the institutional ethics committee of each participating centre with patient consent waived. Patients with stage II-IIIC gastric adenocarcinoma according to American Joint Committee on Cancer, ${ }^{11}$ who had completed curative surgical treatment and who had undergone S-1 adjuvant chemotherapy, were included. Patients with stage IV disease and who had had prior therapy with S-1 in the neoadjuvant setting were excluded.

Adjuvant S-1 was started at least 3 weeks after curative surgery. The intended dose of S-1 was based on that published in the ACTS-GC trial, ${ }^{4}$ and was $40 \mathrm{mg} / \mathrm{m}^{2}$ twice daily for 4 weeks followed by 2 weeks of rest for each cycle. Specifically, during the 
TABLE I. Baseline demographic and clinical characteristics $(n=30)$

\begin{tabular}{|c|c|}
\hline Characteristic & Median (range) or No. (\%) \\
\hline Age (years) & $65.6(27-83)$ \\
\hline \multicolumn{2}{|l|}{ Sex } \\
\hline Male & $18(60.0)$ \\
\hline Female & $12(40.0)$ \\
\hline \multicolumn{2}{|l|}{ ECOG performance status } \\
\hline 0 & $8(26.7)$ \\
\hline 1 & $19(63.3)$ \\
\hline 2 & $3(10.0)$ \\
\hline \multicolumn{2}{|l|}{ HBsAg status } \\
\hline Positive & $2(6.7)$ \\
\hline Negative & $28(93.3)$ \\
\hline \multicolumn{2}{|l|}{ Prior cancer } \\
\hline Yes & $1(3.3)$ \\
\hline No & $29(96.7)$ \\
\hline Height on diagnosis (cm) & $160(145-182)$ \\
\hline Weight on diagnosis (kg) & $55.6(45-83)$ \\
\hline $\mathrm{BMI}$ on diagnosis $\left(\mathrm{kg} / \mathrm{m}^{2}\right)$ & $21.9(19-30)$ \\
\hline BSA at diagnosis $\left(\mathrm{m}^{2}\right)$ & $1.6(1.4-2.0)$ \\
\hline \multicolumn{2}{|l|}{ Ever smoker } \\
\hline Yes & $6(20.0)$ \\
\hline No & $24(80.0)$ \\
\hline \multicolumn{2}{|l|}{ Ever regular alcohol intake } \\
\hline Yes & $5(16.7)$ \\
\hline No & $25(83.3)$ \\
\hline \multicolumn{2}{|l|}{ Site of tumour } \\
\hline Antrum & $12(40.0)$ \\
\hline Body & $9(30.0)$ \\
\hline Body and antrum & $3(10.0)$ \\
\hline Fundus and body & $1(3.3)$ \\
\hline Gastroesophageal junction & $5(16.7)$ \\
\hline \multicolumn{2}{|l|}{ Type of gastrectomy } \\
\hline Total & $11(36.7)$ \\
\hline Partial & $19(63.3)$ \\
\hline \multicolumn{2}{|l|}{ D dissection } \\
\hline D1 & $2(6.7)$ \\
\hline $\mathrm{D} 2$ & $26(86.7)$ \\
\hline $\mathrm{N} / \mathrm{A}$ & $2(6.7)$ \\
\hline \multicolumn{2}{|l|}{ Cancer stage, TNM classification } \\
\hline II & $19(63.3)$ \\
\hline IIIA & $2(6.7)$ \\
\hline IIIB & 7 (23.3) \\
\hline IIIC & $2(6.7)$ \\
\hline \multicolumn{2}{|l|}{ Tumour stage } \\
\hline T1 & $1(3.3)$ \\
\hline $\mathrm{T} 2$ & $5(16.7)$ \\
\hline T3 & $15(50.0)$ \\
\hline T4 & $9(30.0)$ \\
\hline \multicolumn{2}{|l|}{ Nodal stage } \\
\hline NO & $11(36.7)$ \\
\hline N1 & $5(16.7)$ \\
\hline N2 & $7(23.3)$ \\
\hline N3 & 7 (23.3) \\
\hline No. of LN resected & $31(12-77)$ \\
\hline No. of LN involved & $2(0-33)$ \\
\hline \multicolumn{2}{|l|}{ Creatinine clearance (mL/min) } \\
\hline$\geq 60$ & $23(76.7)$ \\
\hline$<60$ & 7 (23.3) \\
\hline Time from surgery to cycle 1 day 1 of $S-1$ (days) & $42(22-162)$ \\
\hline
\end{tabular}

Abbreviations: $\mathrm{BMI}=$ body mass index; $\mathrm{BSA}=$ body surface area; $\mathrm{ECOG}=$ Eastern Cooperative Oncology Group; HBsAg = surface antigen of the hepatitis B virus; LN = lymph nodes; $\mathrm{N} / \mathrm{A}=$ not available; $\mathrm{S}-\mathrm{I}$ = administration of tegafur, gimeracil, and oteracil potassium;TNM = tumour node metastasis treatment weeks, patients with body surface area (BSA) of $<1.25 \mathrm{~m}^{2}$ received $80 \mathrm{mg}$ daily; those with BSA of $1.25 \mathrm{~m}^{2}$ to $<1.5 \mathrm{~m}^{2}$ received $100 \mathrm{mg}$ daily; and those with BSA of $\geq 1.5 \mathrm{~m}^{2}$ received $120 \mathrm{mg}$ daily. As clinically indicated, dose reductions were considered one dose level at a time; in general, one dose level reduction refers to reducing the prior daily dose by $20 \mathrm{mg}$, eg from $120 \mathrm{mg}$ to $100 \mathrm{mg}$ daily. As renal impairment has been associated with increased incidence of myelosuppression, dose reduction by one dose level was made in patients who had a creatinine clearance of $40-49 \mathrm{~mL} / \mathrm{min}$. A maximum of eight 6-weekly cycles were administered. The dose of S-1 was reduced in patients with significant toxicities, as assessed by the respective clinicianin-charge. Complete and differential blood count and serum chemistry were performed before each 6-week cycle. All patients had mid-cycle follow-up with complete and differential blood counts and serum chemistry in the first cycle.

Patient charts were reviewed by investigators at each centre for background information. S-1 chemotherapy records, as well as biochemical and haematological profiles, were extracted. Adverse events were graded according to the National Cancer Institute's Common Terminology Criteria for Adverse Events (version 3.0). ${ }^{12}$ Adverse events were documented during chemotherapy and for 28 days after the last dose of S-1. Dose interruption was defined as a need for either any dose delay and/or dose reduction.

Clinical characteristics are summarised as number of patients and percentage (\%) for categorical variables, and medians with ranges for continuous variables. The frequency of adverse events was tabulated. Factors independently associated with adverse events, dose interruptions, or earlier withdrawal of S-1 were identified using the Pearson's Chi squared $\left(\chi^{2}\right)$ test or the Fisher's exact test if the expected number in any cell was less than five for categorical data or any cell with an expected count of less than one for categorical data, and $t$ test or Wilcoxon rank-sum test for continuous data. A twosided $P$ value of $<0.05$ was considered significant. All statistical analyses were performed with SAS, version 9.3 (SAS Institute Inc, Cory [NC], US).

Disease-free survival (DFS) was calculated as the period from the date of surgery to the date of recurrence or death from any cause; OS was calculated as the period from the date of surgery to the date of death from any cause. Both DFS and OS were estimated using the Kaplan-Meier method.

\section{Results}

\section{Characteristics of patients}

Thirty patients met the eligibility criteria in the six centres during the study period and were enrolled in this study. Their baseline demographic and clinical 
characteristics are shown in Table 1.

There were 18 males and 12 females with a median age of 65.6 years. Of the patients, 27 (90\%) had ECOG (Eastern Cooperative Oncology Group) performance status of 0 to 1 . Total gastrectomy was performed in $11(36.7 \%)$ patients and partial gastrectomy in 19 (63.3\%). D2 dissection was performed in $26(86.7 \%)$ patients and two had D1 dissection; the details of two other patients were unknown. The median number of lymph nodes resected was 31. Cancer stage II disease was present in $19(63.3 \%)$ patients and stage III in $11(36.7 \%)$.

Of the 30 patients, two $(6.7 \%)$, two $(6.7 \%)$, one $(3.3 \%)$, two $(6.7 \%)$, one $(3.3 \%)$, three $(10 \%)$, and 19 (63.3\%) completed one, two, three, four, five, six, and eight cycles of S-1 adjuvant chemotherapy, respectively. At the time of data cut-off on 29 February 2016, one patient was still on S-1, having completed six cycles of treatment. The reasons for treatment withdrawal included toxicities $(n=5,16.7 \%)$, patient refusal $(3,10 \%)$, recurrence $(2,6.7 \%)$, and worsening of pre-existing Parkinson's disease $(1,3.3 \%)$.

\section{Patient survival}

The median follow-up period was 25.3 months (range, 16.3-29.2 months). Three patients died and two experienced recurrence (lung and peritoneum). The 3-year DFS and OS rates were $80.2 \%$ and $85.9 \%$, respectively (Fig).

\section{Tolerability data}

Table 2 presents the haematological and nonhaematological adverse events experienced during treatment. Grade 3-4 haematological adverse events included neutropaenia $(\mathrm{n}=3,10 \%)$, leukopaenia (1, 3.3\%), and anaemia (2, 6.7\%). Grade 3-4 nonhaematological adverse events included nonneutropaenic septic episode (16.7\%), diarrhoea (6.7\%), hyperbilirubinaemia (6.7\%), syncope $(6.7 \%)$, reduced left ventricular ejection function (3.3\%), gouty attack (3.3\%), hypokalaemia (3.3\%), subacute intestinal obstruction (3.3\%), and urticaria (3.3\%).

Of note, 10 patients developed a septic episode; apart from one patient with grade 3 neutropaenic fever, the others were non-neutropaenic. Of the latter, four had grade 3 toxicity, four had grade 2, and one had grade 1 toxicity; in one patient with grade 2 toxicity, the infection was due to pulmonary tuberculosis. This latter patient had a history of ischaemic heart disease and he also developed grade 3 reduced left ventricular ejection function whilst on $\mathrm{S}-1$, as noted above.

Two out of 30 patients were found to be positive for hepatitis B surface antigen. Of these two, one was prescribed prophylactic antiviral therapy and liver function remained normal apart from one isolated episode of grade 2 hyperbilirubinaemia that resolved spontaneously without other hepatic dysfunction; the other patient did not receive prophylactic antiviral therapy but his liver function remained normal throughout S-1 therapy.

There were no treatment-related deaths.

\section{Dose interruptions}

Of the 30 patients, 17 (56.7\%) were commenced on a lower-than-intended dose of S-1. The reason for reducing the first dose was: impaired renal function $(n=6$; with creatinine clearance ranging from 41-48 $\mathrm{mL} / \mathrm{min}$ ), concern of toxicity (6), aged over 70 years (4), and borderline performance status (1); four of these patients had further dose reduction in subsequent cycles. Of the other 13 patients who had the full S-1 dose in cycle 1 , five had a dose reduction from cycle 2 onwards.

Dose delays occurred in 12 (40\%) patients; these were due to delayed bone marrow recovery $(n=3)$, hypokalaemia (2, including 1 who also had delayed bone marrow recovery), diarrhoea (2), sepsis (2), hypoglycaemia (1), impaired renal function (1), reduced weight (1), and abdominal pain (1).

\section{Risk factor analysis}

Potential risk factors for adverse events were assessed (Table 3). Univariate analysis showed that total gastrectomy was significantly associated with haematological adverse events; $90.9 \%$ of patients who had total gastrectomy in contrast to $52.6 \%$ of the patients who had partial gastrectomy experienced grade $2-4$ adverse events $(\mathrm{P}=0.034)$. On univariate analysis, nodal status was significantly associated with non-haematological adverse events; $76.2 \%$ of patients who experienced grade $2-4$ adverse events had nodal disease, while only $33 \%$ of those who had grade $0-1$ adverse events had nodal disease $(\mathrm{P}=0.031)$.

Potential risk factors for earlier withdrawal

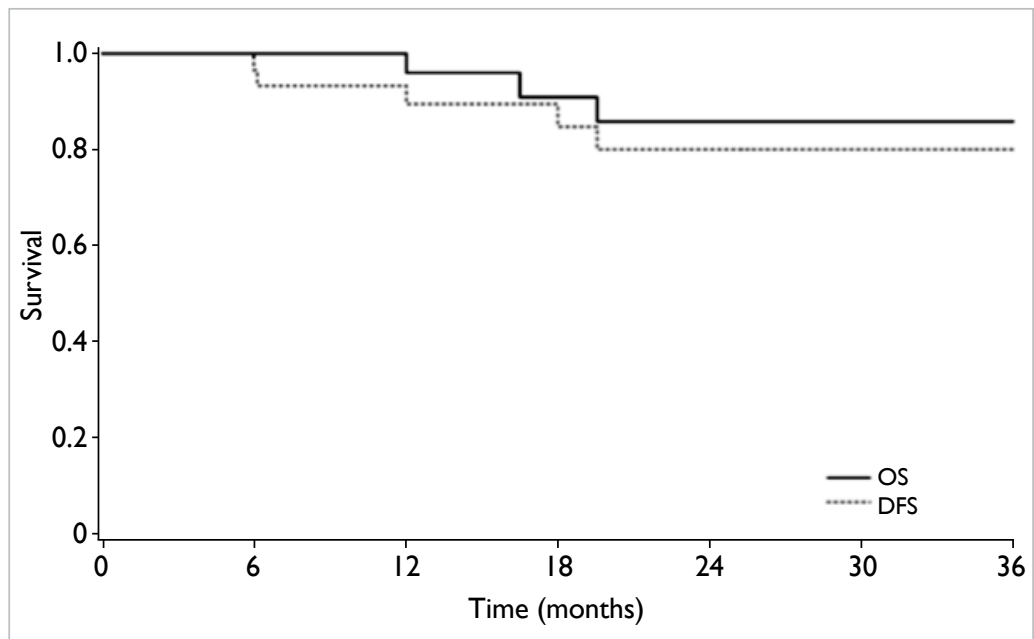

FIG. Kaplan-Meier estimates of disease-free survival (DFS) and overall survival (OS) 
TABLE 2. Haematological and non-haematological adverse events (all grades)

\begin{tabular}{|c|c|c|c|c|c|}
\hline \multirow[t]{2}{*}{ Adverse event } & \multicolumn{5}{|c|}{ Grade $(n=30)$} \\
\hline & 0 & 1 & 2 & 3 & 4 \\
\hline \multicolumn{6}{|l|}{ Haematological } \\
\hline Leukopaenia & 8 & 17 & 4 & 0 & 1 \\
\hline Neutropaenia & 19 & 3 & 5 & 3 & 0 \\
\hline Anaemia & 0 & 14 & 14 & 2 & 0 \\
\hline Thrombocytopaenia & 18 & 12 & 0 & 0 & 0 \\
\hline \multicolumn{6}{|l|}{ Biochemical } \\
\hline Hypokalaemia & 20 & 9 & 0 & 0 & 1 \\
\hline Hyperbilirubinaemia & 15 & 8 & 5 & 2 & 0 \\
\hline Hypoalbuminaemia & 29 & 0 & 1 & 0 & 0 \\
\hline Raised creatinine & 19 & 9 & 2 & 0 & 0 \\
\hline Hyperkalaemia & 26 & 3 & 1 & 0 & 0 \\
\hline Hypoglycaemia & 29 & 0 & 1 & 0 & 0 \\
\hline Uraemia* & 20 & 9 & 0 & 0 & 0 \\
\hline Raised alanine transaminase & 24 & 6 & 0 & 0 & 0 \\
\hline Raised alkaline phosphatase & 22 & 8 & 0 & 0 & 0 \\
\hline Hypernatraemia & 22 & 8 & 0 & 0 & 0 \\
\hline Hyponatraemia & 22 & 8 & 0 & 0 & 0 \\
\hline \multicolumn{6}{|l|}{ Other non-haematological } \\
\hline Septic episode & 20 & 1 & 4 & 5 & 0 \\
\hline Diarrhoea & 9 & 15 & 4 & 2 & 0 \\
\hline Syncope & 28 & 0 & 0 & 2 & 0 \\
\hline Pain (non-specified) & 25 & 3 & 1 & 1 & 0 \\
\hline Reduced LVEF & 29 & 0 & 0 & 1 & 0 \\
\hline Gouty attack & 29 & 0 & 0 & 1 & 0 \\
\hline Subacute intestinal obstruction & 29 & 0 & 0 & 1 & 0 \\
\hline Urticaria & 29 & 0 & 0 & 1 & 0 \\
\hline Anorexia & 19 & 8 & 3 & 0 & 0 \\
\hline Rash & 23 & 5 & 2 & 0 & 0 \\
\hline Weight loss & 27 & 1 & 2 & 0 & 0 \\
\hline Pain (abdomen) & 28 & 0 & 2 & 0 & 0 \\
\hline Hand-foot syndrome & 20 & 9 & 1 & 0 & 0 \\
\hline Nausea & 21 & 8 & 1 & 0 & 0 \\
\hline Fatigue & 28 & 1 & 1 & 0 & 0 \\
\hline Headache & 28 & 1 & 1 & 0 & 0 \\
\hline Vomiting & 28 & 1 & 1 & 0 & 0 \\
\hline Ascites & 29 & 0 & 1 & 0 & 0 \\
\hline Constipation & 29 & 0 & 1 & 0 & 0 \\
\hline Thirsty & 29 & 0 & 1 & 0 & 0 \\
\hline Stomatitis & 18 & 12 & 0 & 0 & 0 \\
\hline Pigmentation & 22 & 8 & 0 & 0 & 0 \\
\hline Insomnia & 28 & 2 & 0 & 0 & 0 \\
\hline Dry skin & 28 & 2 & 0 & 0 & 0 \\
\hline Fever & 28 & 2 & 0 & 0 & 0 \\
\hline Sensory neuropathy & 28 & 2 & 0 & 0 & 0 \\
\hline Pruritus & 28 & 2 & 0 & 0 & 0 \\
\hline Alopecia & 29 & 1 & 0 & 0 & 0 \\
\hline Bloating, abdominal & 29 & 1 & 0 & 0 & 0 \\
\hline Dizziness & 29 & 1 & 0 & 0 & 0 \\
\hline Dry eyes & 29 & 1 & 0 & 0 & 0 \\
\hline Dyspnoea & 29 & 1 & 0 & 0 & 0 \\
\hline Abdominal discomfort & 29 & 1 & 0 & 0 & 0 \\
\hline Hypotension & 29 & 1 & 0 & 0 & 0 \\
\hline Lacrimation & 29 & 1 & 0 & 0 & 0 \\
\hline Lower gastrointestinal haemorrhage & 29 & 1 & 0 & 0 & 0 \\
\hline Menorrhagia & 29 & 1 & 0 & 0 & 0 \\
\hline Musculoskeletal: right groin hernia & 29 & 1 & 0 & 0 & 0 \\
\hline Musculoskeletal: buttock discomfort & 29 & 1 & 0 & 0 & 0 \\
\hline Oedema & 29 & 1 & 0 & 0 & 0 \\
\hline Sexual: right breast swelling and tenderness & 29 & 1 & 0 & 0 & 0 \\
\hline
\end{tabular}

Abbreviation: LVEF = left ventricular ejection function

* Unknown data in I case of S-1 and dose interruptions (dose reductions and/or dose delays) were assessed (Table 4). For earlier S-1 withdrawal, patients who had a history of regular alcohol intake were significantly more likely to have earlier treatment withdrawal than non-drinkers ( $80 \%$ vs $28 \%$; $\mathrm{P}=0.044)$, while eversmokers also had a tendency, though insignificant, for earlier withdrawal than never-smokers (67\% vs 29\%; $\mathrm{P}=0.095$ ). For dose interruptions, univariate analysis showed lower body weight $(\mathrm{P}=0.007)$ and lower BSA ( $\mathrm{P}=0.017)$ were significant associated factors, while lower body mass index (BMI) also had an increased tendency, though insignificant, for dose interruptions $(\mathrm{P}=0.055)$. The median body weight, BMI, and BSA of those patients who had dose interruptions were $54.5 \mathrm{~kg}, 21.4 \mathrm{~kg} / \mathrm{m}^{2}$, and $1.54 \mathrm{~m}^{2}$, respectively; the corresponding data for those who did not require dose interruptions were $64.0 \mathrm{~kg}, 24.8$ $\mathrm{kg} / \mathrm{m}^{2}$, and $1.67 \mathrm{~m}^{2}$, respectively.

\section{Discussion}

Our study results indicate that adjuvant S-1 chemotherapy is feasible for our local patients after curative resection of gastric cancer. With increased awareness of the associated toxicity, S-1 can be offered safely as standard adjuvant therapy. The toxicities experienced by the studied patients were in line with previous findings in Asian patients.,12,13 Grade 3-4 haematological adverse events included thrombocytopaenia and anaemia. Grade 3-4 nonhaematological adverse events that occurred in 5\% or more of the patients included non-neutropaenic septic episode, diarrhoea, hyperbilirubinaemia, and syncope.

Previous studies have investigated factors associated with adverse events during S-1 therapy. In a Korean study of 305 patients given adjuvant S-1 therapy, ${ }^{13}$ total gastrectomy was reported to be an independent risk factor for grade 3-4 haematological toxicities and age $>65$ years was an independent risk factor for grade 3 non-haematological toxicities. Independent risk factors for withdrawal and dose reductions included age $>65$ years and male gender. Total gastrectomy has also been reported to be associated with a significantly greater risk of serious adverse events in another study of Taiwanese gastric cancer patients receiving adjuvant $\mathrm{S}-1 .{ }^{14}$

The reason for the higher incidence of serious adverse events in patients who underwent total gastrectomy whilst receiving S-1 treatment is unknown. In an earlier study, a higher incidence of adverse reactions was observed among patients who received S-1 as adjuvant treatment after gastrectomy, compared with those who had unresectable or recurrent gastric cancer. The investigators suggested the limitation in food intake soon after extensive surgery as a possible cause of exacerbation of adverse reactions such as anorexia and nausea, and proposed 
TABLE 3. Univariate analysis of risk factors for grade $2-4$ adverse events

\begin{tabular}{|c|c|c|c|c|c|c|}
\hline \multirow[t]{2}{*}{ Risk factor } & \multicolumn{3}{|c|}{ Grade 2-4 haematological adverse events* } & \multicolumn{3}{|c|}{$\begin{array}{c}\text { Grade 2-4 non-haematological adverse } \\
\text { events* }\end{array}$} \\
\hline & Grade $0-1(n=10)$ & Grade 2-4 $(n=20)$ & $\mathbf{P}$ valuet & Grade 0-1 (n=9) & Grade 2-4 $(n=21)$ & $\mathbf{P}$ value \\
\hline Age (years) & $67.5(54-83)$ & $64.5(27-78)$ & 0.1363 & $64.0(33-83)$ & $66.0(27-78)$ & 0.9172 \\
\hline Gender & & & 0.3058 & & & 0.2855 \\
\hline Male & 6 & 12 & & 6 & 12 & \\
\hline Female & 4 & 8 & & 3 & 9 & \\
\hline ECOG performance status & & & 0.4114 & & & 0.0717 \\
\hline 0 & 2 & 6 & & 4 & 4 & \\
\hline 1 & 6 & 13 & & 3 & 16 & \\
\hline 2 & 2 & 1 & & 2 & 1 & \\
\hline HBsAg status & & & 0.4598 & & & 0.4828 \\
\hline Positive & 1 & 1 & & 0 & 2 & \\
\hline Negative & 9 & 19 & & 9 & 19 & \\
\hline Height on diagnosis $(\mathrm{cm})$ & $158(145-167)$ & $161(150-182)$ & 0.0936 & $164(148-170)$ & $160(145-182)$ & 0.9097 \\
\hline Weight on diagnosis $(\mathrm{kg})$ & $56.5(48-64.1)$ & $55.6(45-82.8)$ & 0.9649 & $54.8(48-71.9)$ & $56.3(45-82.8)$ & 0.9099 \\
\hline BMI on diagnosis $\left(\mathrm{kg} / \mathrm{m}^{2}\right)$ & $22.7(20.3-30.4)$ & $21.0(19.0-28.9)$ & 0.1588 & $22.2(19.7-25.0)$ & $21.4(19.0-30.4)$ & 0.6669 \\
\hline BSA at diagnosis $\left(m^{2}\right)$ & $1.55(1.39-1.70)$ & $1.57(1.38-1.95)$ & 0.6127 & $1.58(1.39-1.83)$ & $1.55(1.38-1.95)$ & 0.7003 \\
\hline Ever smoker & & & 0.2304 & & & 0.3084 \\
\hline Yes & 3 & 3 & & 1 & 5 & \\
\hline No & 7 & 17 & & 8 & 16 & \\
\hline Ever regular alcohol intake & & & 0.3400 & & & 0.3780 \\
\hline Yes & 1 & 4 & & 1 & 4 & \\
\hline No & 9 & 16 & & 8 & 17 & \\
\hline Type of gastrectomy & & & 0.0338 & & & 0.1937 \\
\hline Total & 1 & 10 & & 2 & 9 & \\
\hline Partial & 9 & 10 & & 7 & 12 & \\
\hline D dissection & & & 0.5301 & & & 0.5365 \\
\hline $\mathrm{D} 1$ & 1 & 1 & & 1 & 1 & \\
\hline $\mathrm{D} 2$ & 9 & 17 & & 8 & 18 & \\
\hline N/A & 0 & 2 & & 0 & 2 & \\
\hline Cancer stage, TNM classification & & & 0.1268 & & & 0.7369 \\
\hline II & 5 & 14 & & 6 & 13 & \\
\hline IIIA & 2 & 0 & & 1 & 1 & \\
\hline IIIB & 3 & 4 & & 2 & 5 & \\
\hline IIIC & 0 & 2 & & 0 & 2 & \\
\hline Tumour stage & & & 0.8964 & & & 0.6503 \\
\hline $\mathrm{T} 1$ & 0 & 1 & & 0 & 1 & \\
\hline T2 & 2 & 3 & & 1 & 4 & \\
\hline T3 & 5 & 10 & & 4 & 11 & \\
\hline T4 & 3 & 6 & & 4 & 5 & \\
\hline Nodal stage & & & 0.8488 & & & 0.0314 \\
\hline No & 4 & 7 & & 6 & 5 & \\
\hline N1 & 1 & 4 & & 0 & 5 & \\
\hline N2 & 3 & 4 & & 3 & 4 & \\
\hline N3 & 2 & 5 & & 0 & 7 & \\
\hline No. of $\mathrm{LN}$ resected & $28.5(12-59)$ & $31.5(12-77)$ & 0.4409 & $23.0(12-50)$ & $32.0(14-77)$ & 0.2046 \\
\hline No. of LN involved & $2.5(0-9)$ & $1.5(0-33)$ & 0.9463 & $0.0(0-6)$ & $3.0(0-33)$ & 0.1007 \\
\hline Creatinine clearance $(\mathrm{mL} / \mathrm{min})$ & & & 0.3427 & & & 0.2469 \\
\hline$\geq 60$ & 8 & 15 & & 6 & 17 & \\
\hline$<60$ & 2 & 5 & & 3 & 4 & \\
\hline Time from surgery to cycle 1 day 1 of $S-1$ (days) & & & 0.2274 & & & 0.2865 \\
\hline$>42$ & 6 & 9 & & 4 & 11 & \\
\hline$\leq 42$ & 4 & 11 & & 5 & 10 & \\
\hline
\end{tabular}

Abbreviations: $\mathrm{BMI}=$ body mass index; BSA = body surface area; ECOG = Eastern Cooperative Oncology Group; HBsAg = surface antigen of the hepatitis

$B$ virus; $L N=$ lymph nodes; N/A = not available; $\mathrm{S}-\mathrm{I}$ = administration of tegafur, gimeracil, and oteracil potassium;TNM = tumour node metastasis

* Data are shown as median (range) or No.

$\dagger$ For continuous data, the $\mathrm{P}$ value was obtained by $t$ test or by Wilcoxon rank-sum test if the continuous data were not normally distributed. For category data, the $P$ value was obtained by Chi squared test or Fisher's exact test if the cells had an expected count of $<5$ or any cell had an expected count of $<1$ 
TABLE 4. Univariate analysis of risk factors for earlier S-I withdrawal and dose interruptions

\begin{tabular}{|c|c|c|c|c|c|c|}
\hline \multirow[t]{2}{*}{ Risk factor } & \multicolumn{3}{|c|}{ Earlier S-1 withdrawal } & \multicolumn{3}{|c|}{ Dose interruptions } \\
\hline & $\begin{array}{l}\text { Received } 8 \\
\text { cycles of S-1 } \\
(n=19)^{\star}\end{array}$ & $\begin{array}{c}\text { Withdrawal of } \\
\text { S-1 before cycle } \\
8(n=11)^{\star}\end{array}$ & P value $†$ & $\begin{array}{l}\text { No dose } \\
\text { interruptions } \\
(n=6)^{\star}\end{array}$ & $\begin{array}{c}\text { Dose } \\
\text { interruptions } \\
(n=24)^{\star}\end{array}$ & $\mathbf{P}$ value \\
\hline Age (years) & $66(37-78)$ & $65.0(27-83)$ & 0.4845 & $65.5(63-71)$ & $65.5(27-83)$ & 0.3252 \\
\hline Gender & & & 0.2884 & & & 0.1732 \\
\hline Male & 11 & 7 & & 5 & 13 & \\
\hline Female & 8 & 4 & & 1 & 11 & \\
\hline ECOG performance status & & & 0.6575 & & & 0.4712 \\
\hline 0 & 4 & 4 & & 1 & 7 & \\
\hline 1 & 13 & 6 & & 5 & 14 & \\
\hline 2 & 2 & 1 & & 0 & 3 & \\
\hline HBsAg status & & & 0.3931 & & & 0.6345 \\
\hline Positive & 2 & 0 & & 0 & 2 & \\
\hline Negative & 17 & 11 & & 6 & 22 & \\
\hline Height on diagnosis (cm) & $160(145-169)$ & $160(148-182)$ & 0.3762 & $167(145-182)$ & 160 (148-169) & 0.1603 \\
\hline Weight on diagnosis $(\mathrm{kg})$ & $56.9(45-80.5)$ & $52.8(48-82.8)$ & 0.5468 & $64.0(56.9-82.8)$ & $54.5(45-80.5)$ & 0.0065 \\
\hline BMI on diagnosis $\left(\mathrm{kg} / \mathrm{m}^{2}\right)$ & $22.2(19.0-30.4)$ & $20.6(19-25.7)$ & 0.3656 & $24.8(20.0-30.4)$ & $21.4(19-28.9)$ & 0.0548 \\
\hline BSA at diagnosis $\left(\mathrm{m}^{2}\right)$ & $1.56(1.39-1.78)$ & $1.53(1.38-1.95)$ & 0.9485 & $1.67(1.55-1.95)$ & $1.54(1.38-1.78)$ & 0.0170 \\
\hline Ever smoker & & & 0.0950 & & & 0.2684 \\
\hline Yes & 2 & 4 & & 2 & 4 & \\
\hline No & 17 & 7 & & 4 & 20 & \\
\hline Ever regular alcohol intake & & & 0.0440 & & & 0.4474 \\
\hline Yes & 1 & 4 & & 1 & 4 & \\
\hline No & 18 & 7 & & 5 & 20 & \\
\hline Type of gastrectomy & & & 0.1221 & & & 0.2154 \\
\hline Total & 5 & 6 & & 1 & 10 & \\
\hline Partial & 14 & 5 & & 5 & 14 & \\
\hline D dissection & & & 0.0973 & & & 0.5616 \\
\hline D1 & 2 & 0 & & 0 & 2 & \\
\hline D2 & 17 & 9 & & 6 & 20 & \\
\hline $\mathrm{N} / \mathrm{A}$ & 0 & 2 & & 0 & 2 & \\
\hline Cancer stage, TNM classification & & & 0.6993 & & & 0.1735 \\
\hline II & 12 & 7 & & 2 & 17 & \\
\hline IIIA & 2 & 0 & & 1 & 1 & \\
\hline IIIB & 4 & 3 & & 3 & 4 & \\
\hline IIIC & 1 & 1 & & 0 & 2 & \\
\hline Tumour stage & & & 0.1079 & & & 0.5840 \\
\hline T1 & 0 & 1 & & 0 & 1 & \\
\hline $\mathrm{T} 2$ & 5 & 0 & & 0 & 5 & \\
\hline T3 & 10 & 5 & & 4 & 11 & \\
\hline T4 & 4 & 5 & & 2 & 7 & \\
\hline Nodal stage & & & 0.9528 & & & 0.4695 \\
\hline No & 7 & 4 & & 1 & 10 & \\
\hline N1 & 3 & 2 & & 2 & 3 & \\
\hline N2 & 5 & 2 & & 2 & 5 & \\
\hline N3 & 4 & 3 & & 1 & 6 & \\
\hline No. of LN resected & $31(12-51)$ & $36(19-77)$ & 0.2912 & $32(19-59)$ & $31(12-77)$ & 0.6591 \\
\hline No. of LN involved & $2(0-33)$ & $2(0-20)$ & 0.1000 & $2.5(0-9)$ & $1.0(0-33)$ & 0.6336 \\
\hline Creatinine clearance (mL/min) & & & 0.3141 & & & 0.1700 \\
\hline$\geq 60$ & 15 & 8 & & 6 & 17 & \\
\hline$<60$ & 4 & 3 & & 0 & 17 & \\
\hline Time from surgery to cycle 1 day 1 of $S-1$ (days) & & & 0.7048 & & & 1.0000 \\
\hline$>42$ & 9 & 6 & & 3 & 12 & \\
\hline$\leq 42$ & 10 & 5 & & 3 & 12 & \\
\hline
\end{tabular}

Abbreviations: BMI = body mass index; BSA = body surface area; ECOG = Eastern Cooperative Oncology Group; HBsAg = surface antigen of the hepatitis

$\mathrm{B}$ virus; $\mathrm{LN}=$ lymph nodes; N/A = not available; $\mathrm{S}-\mathrm{I}$ = administration of tegafur, gimeracil, and oteracil potassium; TNM = tumour node metastasis

* Data are shown as median (range) or No.

+ For continuous data, the $P$ value was obtained by $t$ test or by Wilcoxon rank-sum test if the continuous data were not normally distributed. For category data, the $P$ value was obtained by Chi squared test or Fisher's exact test if the cells had an expected count of $<5$ or any cell had an expected count of $<1$ 
that a delay in the start of drug administration after gastrectomy may prevent such adverse events. ${ }^{15}$ In another study, Taiwanese patients received palliative S-1 for advanced gastric cancer at a median initial dose of $37.0 \mathrm{mg} / \mathrm{m}^{2}$. Twelve patients had singledosing pharmacokinetic study on day 1 , and seven took part in a multiple-dosing pharmacokinetic study on day 28 . The results indicated that the steady-state pharmacokinetics of 5-FU, CDHP and Oxo could be predicted from single-dose pharmacokinetic study. Six patients who underwent gastrectomy had a similar pharmacokinetic profile to another six patients who did not undergo gastrectomy. ${ }^{16}$ Nonetheless, definitive data regarding the pharmacokinetic profile of S-1 components in patients who underwent different degrees of gastrectomy are lacking.

Other factors that have been reported to be associated with treatment-related adverse events include low body mass and impaired renal function. ${ }^{16}$ These were supported by the present study in which lower body weight, BMI, and BSA were associated with an increased likelihood of dose interruptions. Earlier reports have shown that impaired renal function will reduce CDHP clearance and result in a prolonged high concentration of 5-FU in plasma, and thereby lead to more severe myelosuppression. ${ }^{8,17}$ Although impaired renal function was not identified as a risk factor for adverse events in this study, it has to be noted that all patients who had subnormal creatinine clearance were offered S-1 at lower doses at treatment initiation; this could have prevented the occurrence of severe adverse events.

The present study was limited by its retrospective nature and the limited number of patients accrued. Although there is a lack of information about patient co-morbidities, the current data suggest that patients who had a history of regular alcohol intake had an increased likelihood of earlier treatment withdrawal. The survival data are immature due to short follow-up. The findings, however, lend support to a published report on the acceptable toxicity profile and tolerability of S-1 as adjuvant therapy after curative gastric surgery for gastric cancer. ${ }^{4,13,14}$ Potential risk factors for severe adverse events are suggested. Due to the small sample size and retrospective nature of this study, a prospective study with a larger patient population is needed to confirm these findings. An awareness of treatment-related adverse events as well as potential associated factors may aid clinicians in managing patients in whom S-1 therapy is planned, and thereby improve treatment compliance and clinical outcome.

\section{Conclusions}

Adjuvant S-1 therapy has a tolerable toxicity profile among local patients who have undergone curative resection for gastric cancer. For gastric cancer patients in whom adjuvant S-1 therapy is planned, those with identifiable risk factors should be closely monitored for adverse events during treatment. This may enable earlier intervention with supportive therapy and optimise treatment outcome.

\section{Acknowledgements}

The authors gratefully acknowledge Mr Edward Choi for his valuable statistical advice. We thank Drs Chiching Law, Hoi-leung Leung, and Chung-kong Kwan of the Department of Clinical Oncology, United Christian Hospital for their support in this study.

\section{Declaration}

This study has been supported by an educational grant from Taiho Pharma Singapore Pte. Ltd. W Yeo has received honorarium for advisory role for Eli Lilly, Novartis, Pfizer, and Bristol Myers Squibb and has received research grant from Novartis over the past 12 months. KO Lam has been an advisor for Amgen, Eli Lilly, Roche, Sanofi-Aventis, and has received honorarium from Amgen, Bayer, Eli Lilly, Merck, Sanofi-Aventis, Taiho and research grant from Bayer, Roche, and Taiho. Authors not named here have disclosed no conflicts of interest.

\section{References}

1. Ferlay J, Shin HR, Bray F, Forman D, Mathers C, Parkin DM. GLOBOCAN 2008: Cancer incidence and mortality worldwide: IARC CancerBase No. 10. Lyon, France: International Agency for Research on Cancer; 2010. Available from: http://globocan.iarc.fr. Accessed 12 Oct 2011.

2. Gallo A, Cha C. Updates on esophageal and gastric cancers. World J Gastroenterol 2006;12:3237-42.

3. GASTRIC (Global Advanced/Adjuvant Stomach Tumor Research International Collaboration) Group, Paoletti $\mathrm{X}$, Oba $\mathrm{K}$, et al. Benefit of adjuvant chemotherapy for resectable gastric cancer: a meta-analysis. JAMA 2010;303:1729-37.

4. Sakuramoto S, Sasako M, Yamaguchi T, et al. Adjuvant chemotherapy for gastric cancer with S-1, an oral fluoropyrimidine. N Engl J Med 2007;357:1810-20.

5. Bang YJ, Kim YW, Yang HK, et al. Adjuvant capecitabine and oxaliplatin for gastric cancer after D2 gastrectomy (CLASSIC): a phase 3 open-label, randomised controlled trial. Lancet 2012;379:315-21.

6. Shirasaka T, Shimamato Y, Ohshimo H, et al. Development of a novel form of an oral 5-fluorouracil derivative (S-1) directed to the potentiation of the tumor selective cytotoxicity of 5-fluorouracil by two biochemical modulators. Anticancer Drugs 1996;7:548-57.

7. Kubota T. The role of $\mathrm{S}-1$ in the treatment of gastric cancer. Br J Cancer 2008;98:1301-4.

8. Hirata K, Horikoshi N, Aiba K, et al. Pharmacokinetic study of S-1, a novel oral fluorouracil antitumor drug. Clin Cancer Res 1999;5:2000-5.

9. Chu QS, Hammond LA, Schwartz G, et al. Phase I and pharmacokinetic study of the oral fluoropyrimidine S-1 on 
a once-daily-for-28-day schedule in patients with advanced malignancies. Clin Cancer Res 2004;10:4913-21.

10. Ajani JA, Faust J, Ikeda K, et al. Phase I pharmacokinetic study of S-1 plus cisplatin in patients with advanced gastric carcinoma. J Clin Oncol 2005;23:6957-65.

11. Edge SB, Byrd DR, Compton CC, Fritz AG, Greene FL, Trotti A. American Joint Committee on Cancer. Cancer Staging Manual. 7th ed. Chicago: Springer; 2010.

12. Trotti A, Colevas AD, Setser A, et al. CTCAE v3.0: development of a comprehensive grading system for the adverse effects of cancer treatment. Semin Radiat Oncol 2003;13:176-81.

13. Jeong JH, Ryu MH, Ryoo BY, et al. Safety and feasibility of adjuvant chemotherapy with S-1 for Korean patients with curatively resected advanced gastric cancer. Cancer Chemother Pharmacol 2012;70:523-9.
14. Chou WC, Chang CL, Liu KH, et al. Total gastrectomy increases the incidence of grade III and IV toxicities in patients with gastric cancer receiving adjuvant TS-1 treatment. World J Surg Oncol 2013;11:287.

15. Kinoshita T, Nashimoto A, Yamamura Y, et al. Feasibility study of adjuvant chemotherapy with S-1 (TS-1; tegafur, gimeracil, oteracil potassium) for gastric cancer. Gastric Cancer 2004;7:104-9.

16. Chen JS, Chao Y, Hsieh RK, et al. A phase II and pharmacokinetic study of first line S-1 for advanced gastric cancer in Taiwan. Cancer Chemother Pharmacol 2011;67:1281-9.

17. Koizumi W, Kurihara M, Nakano S, Hasegawa K. Phase II study of S-1, a novel oral derivative of 5-fluorouracil, in advanced gastric cancer. For the S-1 Cooperative Gastric Cancer Study Group. Oncology 2000;58:191-7. 